\title{
IMAGE TRANSMISSION IN OFDM USING M-ARY PSK MODULATION SCHEMES -A COMPARITIVE STUDY
}

\author{
N.Praba ${ }^{1}$, K.M.Ravikumar ${ }^{2}$ \\ ${ }^{1}$ Dr.K.M.Ravikumar,Professor\&HOD,E\&C Department,SJCIT,chikkabalapur \\ ${ }^{2}$ N.Praba, Asso.Professor,G.C.E,Ramanagaram
}

\begin{abstract}
Image transmission in OFDM could be done using various modulation techniques. Digital images are prone to a wide variety of noises. The various noises are salt and pepper noise, Gaussian noise, speckle noise. The performance of the OFDM system for digital image transmission using four different modulation techniques namely BPSK,QPSK,16-PSK and 256-PSK are analyzed. The image is corrupted by additive white Gaussian noise(AWGN) which is added in the communication channel. The results show that OFDM systems with BPSK modulation or QPSK modulation performs well for image transmission under noisy channels and with SNR $\leq 12 \mathrm{~dB}$ compared to OFDM systems with 16-PSK or 256-PSK modulation. The simulation is done in MATLAB.
\end{abstract}

Keywords - Orthogonal frequency division multiplexing(OFDM), Bit Error Rate (BER),Phase shift keying(PSK), additive white Gaussian noise (AWGN).Inter-symbol interference(ISI)

\section{INTRODUCTION}

Image transmission in an OFDM system has gained interest in recent years. Since images are prone to wide variety of noises in the communication channel, it should be de-noised using filters. A wide variety of filters are available like average filter, Gaussian filter, weighted median filter, weiner filter and so on[3]. However since OFDM systems have high PAPR ratio, have high resistance to frequency selective fading due to the orthogonality of large number of narrow-band sub-carriers. Due to this property the ISI is also greatly reduced[4].

The input file is taken from an image file persan.jpg, available as a MATLAB image, the image converted to a grayscale image and stored in a bitmap file persan.bmp. The image is converted into symbols the size of each is determined by the type of modulation. The data is the separated into frames and the modulated by the modulator frame by frame. All sub-carriers are realized together using IFFT which is computationally very efficient and also cost effective.[2] The frequency domain representation of the data is converted into time domain using IFFT. The higher the IFFT_ size , the more complex the OFDM system is and a higher data rate is achieved.

Cyclic prefix are added along with frame guards in between the modulated frames. The cascaded frames are then transmitted after converting into analog format using DAC and an RF-front end amplifier. The communication channel is modeled using AWGN and amplitude clipping introduced in the channel. Since OFDM signal has a high PAPR they are subjected to amplitude clipping introduced in the channel.
At the receiver an RF-front end amplifier amplifies the signal and the DAC converts the analog frames to digital. An envelope detector acts as a frame detector detecting the start and end of the every frame.The frames are converted to serial data and using FFT, they are converted into symbols in the spectral space.The carriers are then extracted and the symbols demodulated and the frames are cascaded and the image reproduced. The simplified block diagram of the OFDM Transmitter is shown in figure 1.

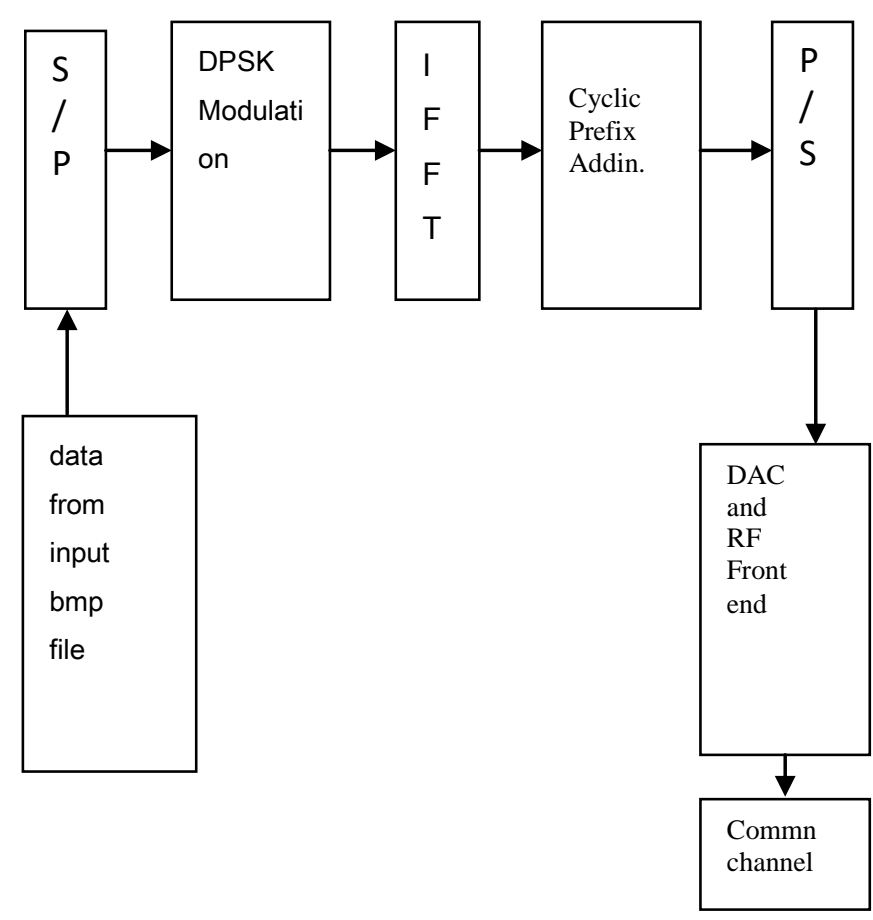

Fig 1. Block diagram of OFDM transmitter 


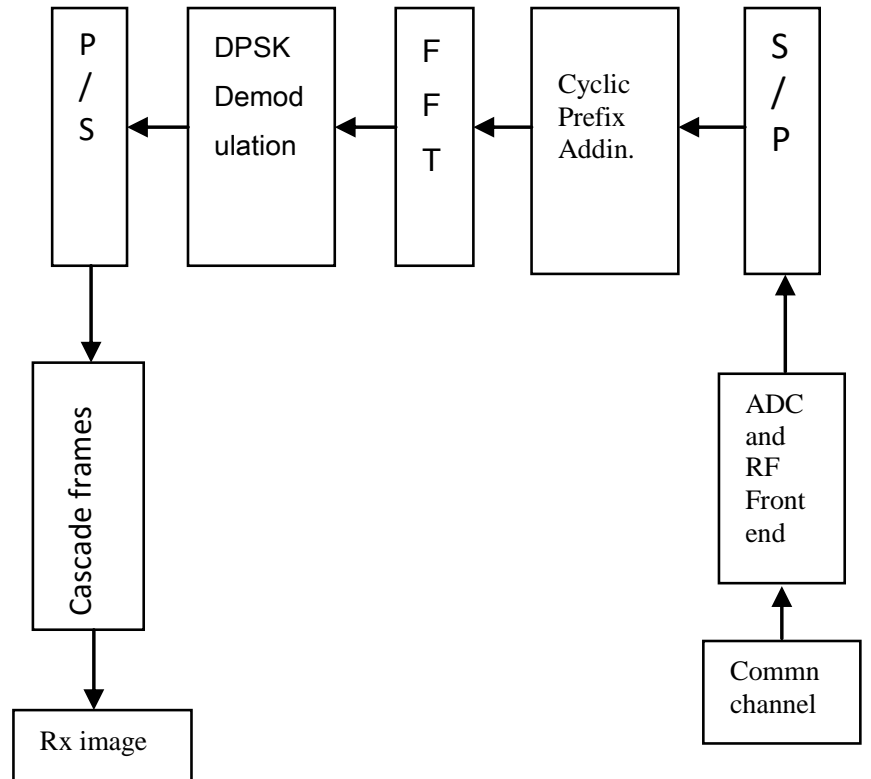

Fig 2. Block diagram of OFDM Receiver

The usage of cyclic prefix and coding techniques help to reduce AWGN[1] to a certain extent, but still its effect is more pronounced in image transmission over noisy channels when $\mathrm{SNR} \leq 12 \mathrm{~dB}$.

\section{SIMULATION}

The input image file is a bitmap file named persan image.bmp. The main program OFDM_image_sim.m takes the IFFT_size,Type of modulation,No.of carriers as input along with SNR value and amplitude clipping value introduced by the channel.These parameters are saved in the parameters_OFDM.m file and this function
parameters_OFDM..m is called from the main program. The symbol size is determined by the choice of modulation scheme. The base band data is saved for calculations of errors finally. A frame guard is added to each frame of the modulated signal.

The signal is differentially encoded before modulation to increase security and make the signal less susceptible to noise. The time taken by the transmitter and the PAPR ratio at the entry and exit of the channel are calculated and also displayed.

The envelope detector is modeled in the file framedetect.m and the image is received frame by frame.The start and end of the data frames and only the frames that contain useful information are detected. The received frames are cascaded to obtain the received image and it is saved in the output file persan image_OFDM.bmp. The time taken by the receiver to receive the data(from data reception to data storage ) is calculated and displayed.

The errors namely BER,Average phase error,\% error of the pixels in the received image calculated and displayed.The results of the simulation is shown in Table1. This clearly indicates the comparison between four different modulation schemes for image transmission..The output images for different modulation schemes for different values of SNR are shown in fig. 3

The fig. 3 shows the transmitted and received images of persan under BPSK modulation scheme in the OFDM Transmitter.

\section{BPSK}
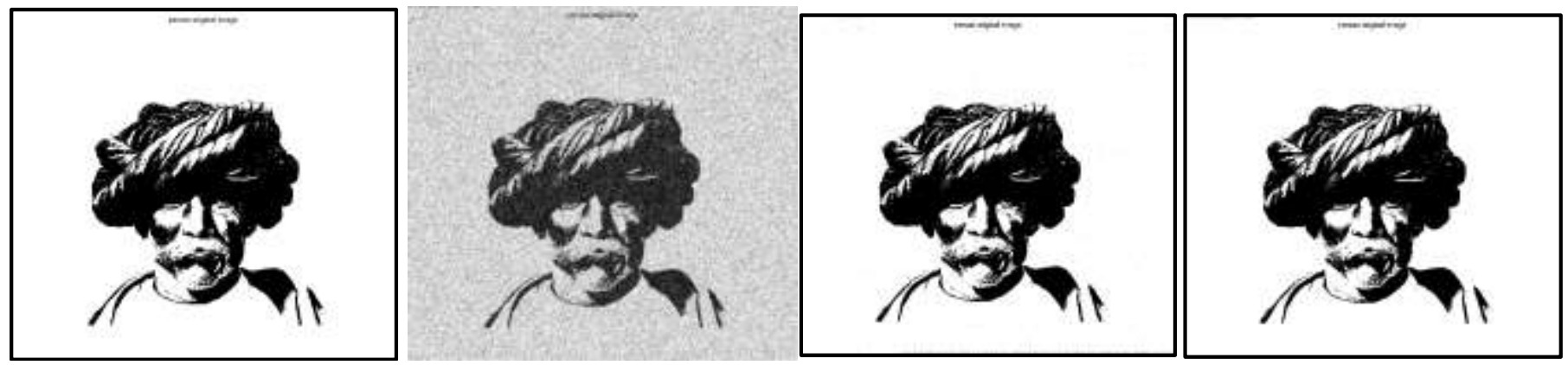

Fig 3. a)original Transmitted image of persan $\mathrm{b})$ received image $(\mathrm{SNR}=0 \mathrm{~dB})$ of persan

c) received image $(\mathrm{SNR}=6 \mathrm{~dB})$ of persan $\mathrm{d})$ received image $(\mathrm{SNR} \geq 12 \mathrm{~dB})$ of persan

The fig. 4 shows the transmitted and received images of persan under QPSK modulation scheme in the OFDM Transmitter. The received images are shown for $\mathrm{SNR}=0 \mathrm{db}$,
$6 \mathrm{db}, \geq 12 \mathrm{db}$ The Tx and Rx runtime are reduced compared to BPSK. The BER has increased significantly and the hence the \% error of pixels in the received image is higher. 


\section{QPSK}

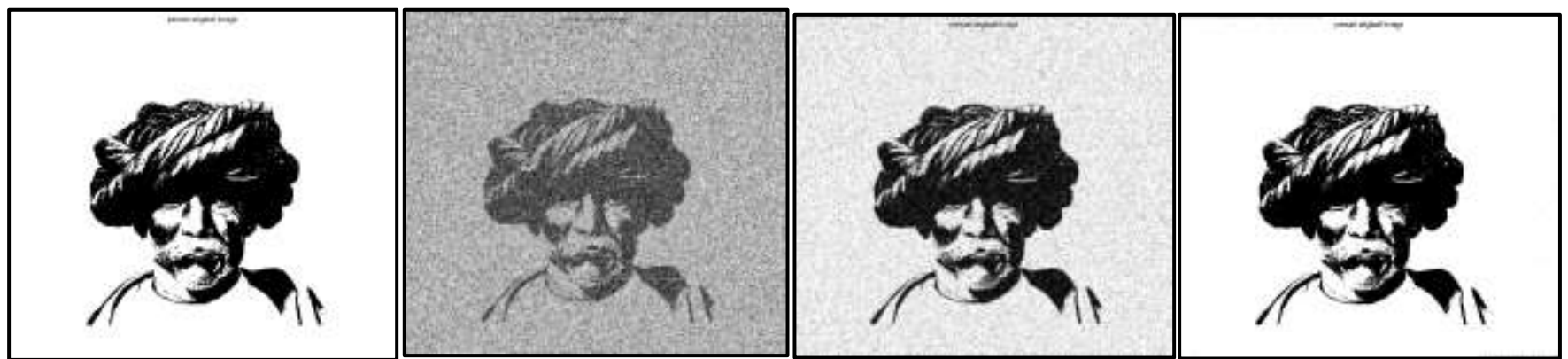

Fig 4a) original Transmitted image of persan $\mathrm{b})$ received image $(\mathrm{SNR}=0 \mathrm{~dB})$ of persan $\mathrm{c})$ received image $(\mathrm{SNR}=6 \mathrm{~dB})$ of persan $\mathrm{d})$ received image $(\mathrm{SNR} \geq 12 \mathrm{~dB})$ of persan

The fig. 5 shows the transmitted and received images of persan under 16-PSK modulation scheme in the OFDM Transmitter. The received images are shown for $\mathrm{SNR}=0 \mathrm{db}$, $6 \mathrm{db}, 12 \mathrm{db}$ and,$\geq 24 \mathrm{~dB}$. The Tx and Rx runtime are reduced compared to QPSK. The BER has increased significantly and the hence the \% error of pixels in the received image is higher for $\mathrm{SNR} \leq 12 \mathrm{~dB}$

\section{6-PSK}

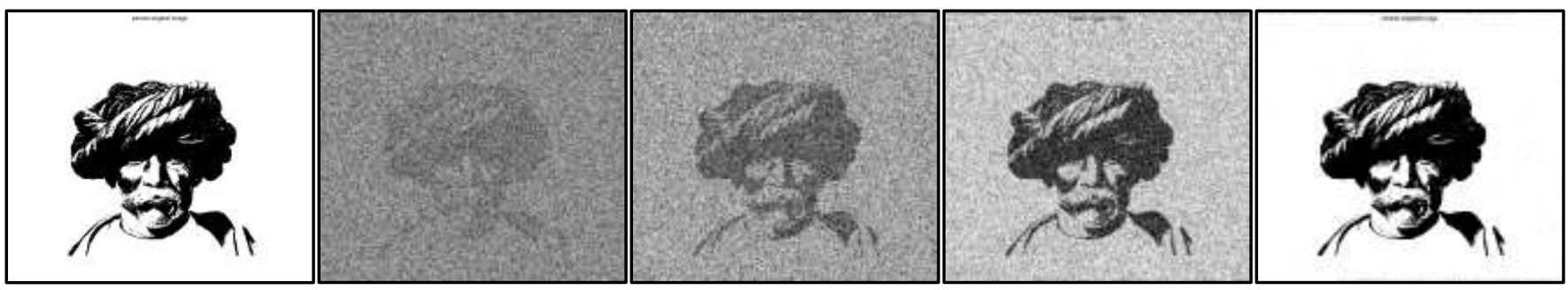

Fig 5a) original Transmitted image of persan $\mathrm{b})$ received image $(\mathrm{SNR}=0 \mathrm{~dB})$ of persan $\mathrm{c})$ received image $(\mathrm{SNR}=6 \mathrm{~dB})$ of persan $\mathrm{d})$ received image $(S N R=12 \mathrm{~dB})$ of persan $\mathrm{e})$ received image $(\mathrm{SNR} \geq 24 \mathrm{~dB})$ of persan

The fig. 6 shows the the transmitted and received images of persan under 256-PSK modulation scheme in the OFDM Transmitter The received images are shown for $\mathrm{SNR}=0 \mathrm{~dB}$, $6 \mathrm{~dB}, 12 \mathrm{~dB}$ and,$\geq 24 \mathrm{~dB}$. The Tx and $\mathrm{Rx}$ runtime are reduced compared to 16-PSK. The BER has increased significantly and the hence the $\%$ error of pixels in the received image is higher for SNR $<24 \mathrm{~dB}$
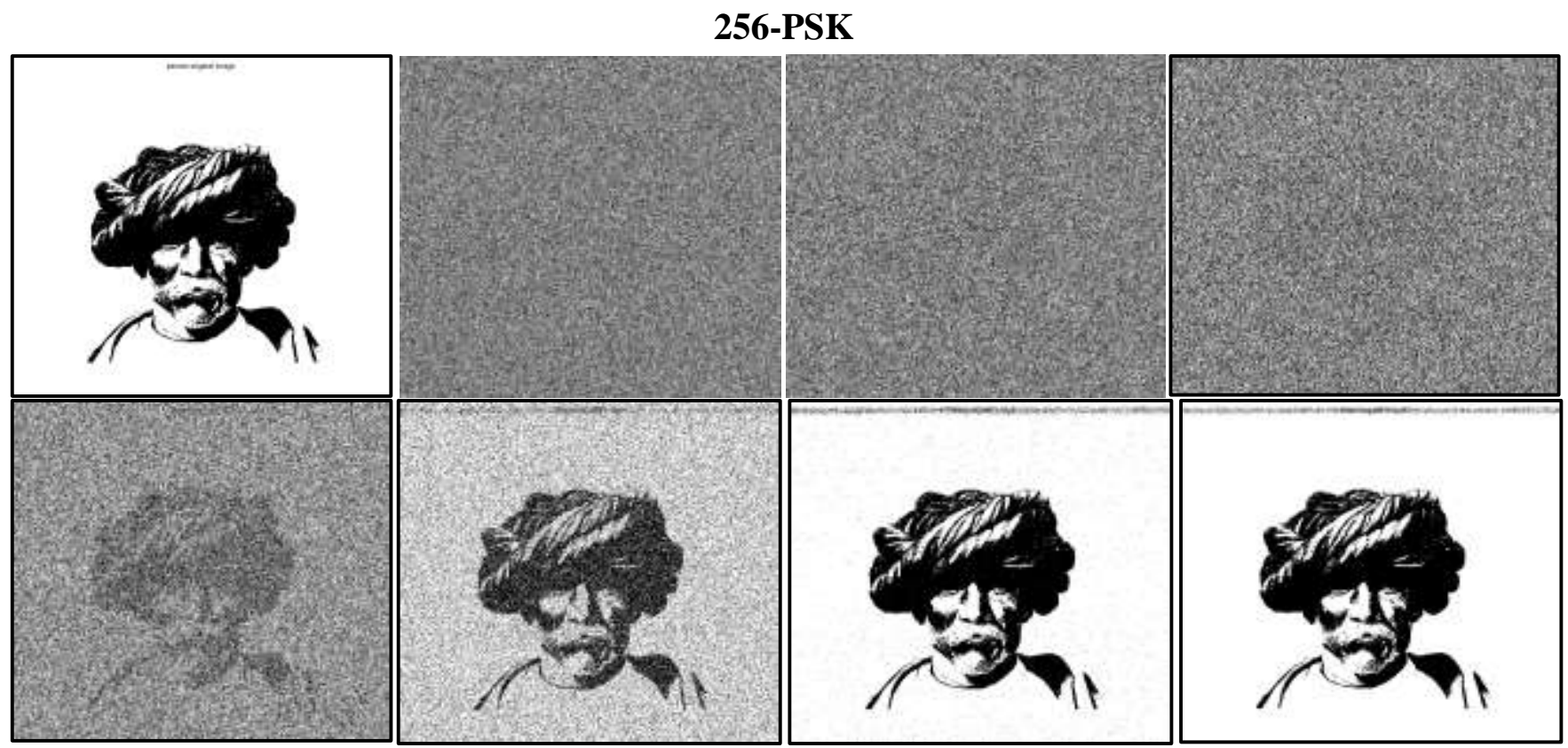

Fig6a) original Transmitted image of persan $\mathrm{b})$ received image $(\mathrm{SNR}=0 \mathrm{~dB})$ of persan $\mathrm{c})$ received image $(\mathrm{SNR}=6 \mathrm{~dB})$ of persan $\mathrm{d})$ received image $(\mathrm{SNR}=12 \mathrm{~dB})$ of persan $\mathrm{e})$ received image $(\mathrm{SNR}=24 \mathrm{~dB})$ of persan $\mathrm{f})$ received image $(\mathrm{SNR}=36 \mathrm{~dB})$ of persan $\mathrm{g})$ received image $(S N R=48 \mathrm{~dB})$ of persan $\mathrm{h})$ received image $(S N R \geq 60 \mathrm{~dB})$ of persan 
Table I. Results

\begin{tabular}{|l|l|l|l|l|l|l|l|l|l|l|}
\hline Modulation & $\begin{array}{l}\text { IFFT } \\
\text { Size }\end{array}$ & $\begin{array}{l}\text { No of } \\
\text { carriers }\end{array}$ & SNR & $\begin{array}{l}\text { PAPR } \\
\text { (entry) }\end{array}$ & $\begin{array}{l}\text { PAPR } \\
\text { (exit) }\end{array}$ & BER & $\begin{array}{l}\text { Tx } \\
\text { Run } \\
\text { Time }\end{array}$ & $\begin{array}{l}\text { Rx } \\
\text { Run } \\
\text { Time }\end{array}$ & $\begin{array}{l}\text { Average } \\
\text { phase } \\
\text { rror }\end{array}$ & $\begin{array}{l}\text { \% error of } \\
\text { pixels of Rx } \\
\text { image }\end{array}$ \\
\hline BPSK & 1024 & 500 & 0 & 14.53 & 13.68 & 17.8 & 13.9 & 15.9 & 52.11 & 79.06 \\
\hline BPSK & 1024 & 500 & 6 & 14.31 & 11.92 & 1.25 & 31.9 & 15.7 & 24.6 & 9.29 \\
\hline BPSK & 1024 & 500 & 12 & 15.53 & 10.18 & 0.01 & 31.4 & 14.7 & 11.4 & 0.03 \\
\hline BPSK & 1024 & 500 & 24 & 14.74 & 6.51 & 0 & 13.7 & 15.7 & 0.711 & 0 \\
\hline QPSK & 1024 & 500 & 0 & 14.05 & 13.72 & 46.12 & 12.3 & 6.57 & 51.45 & 91.59 \\
\hline QPSK & 1024 & 500 & 6 & 14.32 & 12.86 & 13.01 & 13 & 7.07 & 23.82 & 42.52 \\
\hline QPSK & 1024 & 500 & 12 & 14.050 & 10.95 & 0.308 & 12.4 & 6.37 & 11.48 & 0.979 \\
\hline QPSK & 1024 & 500 & 24 & 14.27 & 9.18 & 0.09 & 12.5 & 6.75 & 3.42 & 0.12 \\
\hline 16-PSK & 1024 & 500 & 0 & 13.53 & 13.52 & 84.99 & 5.81 & 3.95 & 51.49 & 97.75 \\
\hline 16-PSK & 1024 & 500 & 6 & 13.711 & 12.16 & 69.35 & 6.22 & 3.92 & 23.77 & 90.58 \\
\hline 16-PSK & 1024 & 500 & 12 & 13.73 & 10.71 & 42.51 & 6.15 & 3.86 & 11.58 & 66.857 \\
\hline 16-PSK & 1024 & 500 & 24 & 13.85 & 8.83 & 0.77 & 6.98 & 4.01 & 3.46 & 1.16 \\
\hline 256-PSK & 1024 & 500 & 0 & 14.26 & 13.18 & 99.04 & 3.49 & 3.99 & 51.11 & 99.04 \\
\hline 256-PSK & 1024 & 500 & 6 & 12.48 & 12.03 & 98.04 & 4.12 & 3.94 & 24.17 & 98 \\
\hline 256-PSK & 1024 & 500 & 12 & 13.31 & 10.21 & 95.95 & 3.97 & 3.46 & 11.59 & 95.95 \\
\hline 256-PSK & 1024 & 500 & 24 & 12.62 & 7.83 & 88.9 & 3.71 & 3.13 & 2.79 & 83.96 \\
\hline
\end{tabular}
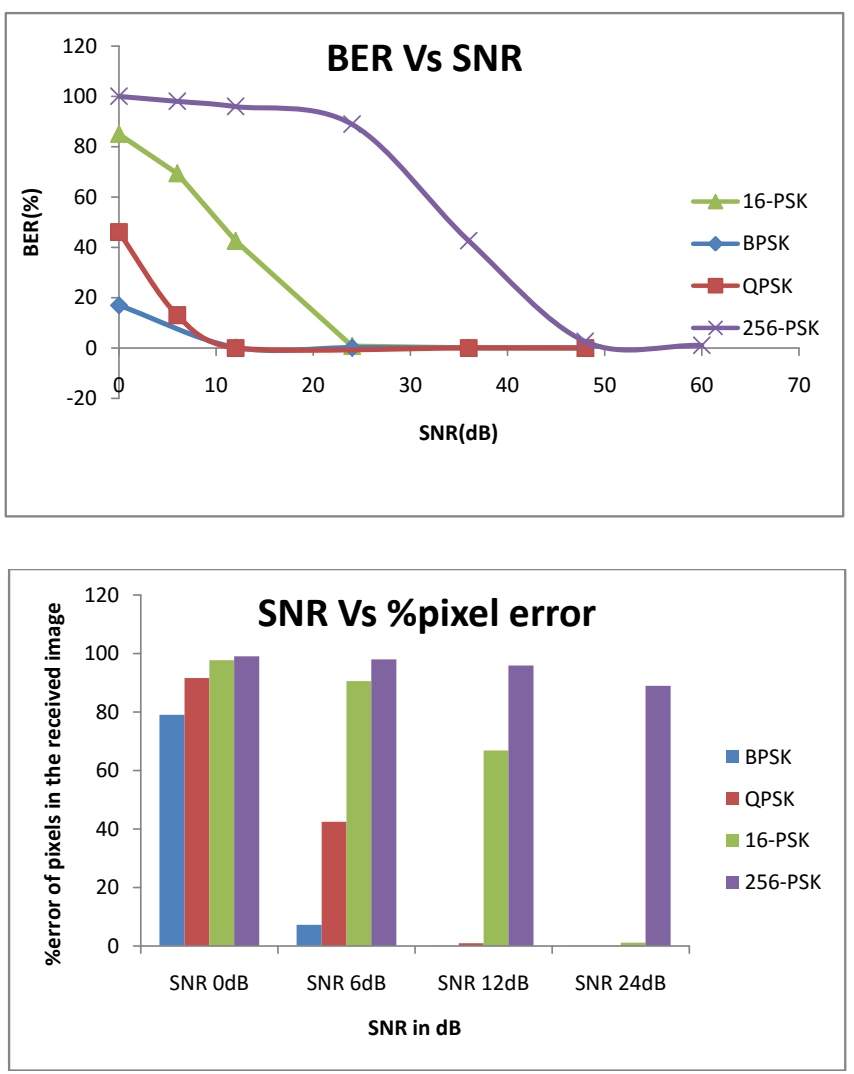

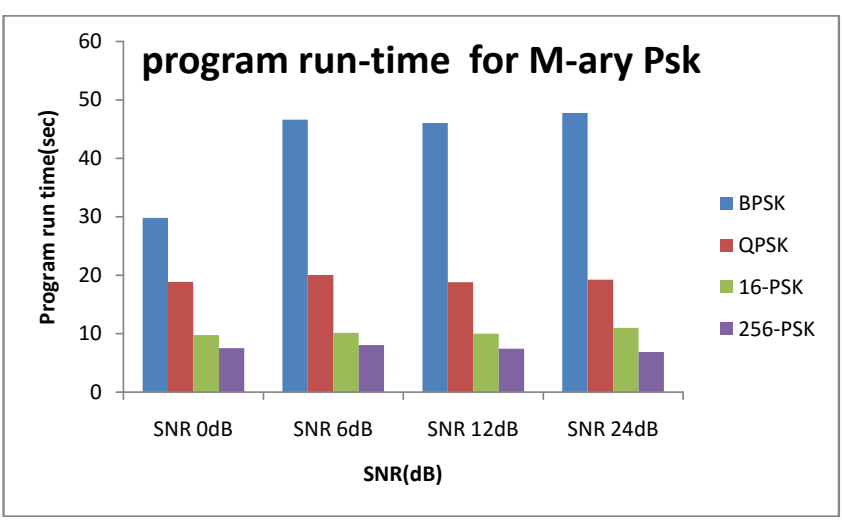

\section{CONCLUSION}

The BER is inversely proportional to SNR.From the simulation results, it can be seen that for extremely noisy channels(SNR $\leq 6 \mathrm{~dB})$ BPSK modulation is the best for image Transmission in OFDM with lesser BER. In terms of fairly noisy channels(SNR $\geq 6 \mathrm{~dB})$, QPSK modulation is the best for image transmission in OFDM as it gives fairly lesser BER, higher data rate, lesser \%pixel error and hence the received image is fairly good. For less noisy channels(SNR $\geq 12 \mathrm{~dB}$ ) 16-PSK gives a higher data rate. The 256-PSK modulation scheme gives highest data rate but correspondingly the BER is higher and also the reception of images is satisfactory only for very high $\mathrm{SNR}(\mathrm{SNR} \geq 60 \mathrm{~dB})$. In short $16-\mathrm{PSK}$ and 256-PSK require a higher SNR to receive an image of acceptable quality.However by using wavelet transform the 
BER of OFDM systems using 16-PSK and 256-PSK systems can be greatly improved.

\section{REFERENCES}

[1]. Tareq Y. Al-Naffouri, Ahmed A. Quadeer, and Giuseppe Caire, Fellow, IEEE, Impulse Noise Estimation and Removal for OFDM Systems", IEEE TRANSACTIONS ON COMMUNICATIONS, VOL. 62, NO. 3, MARCH 2014

[2]. Pankaj Hedaoo and Swati S Godbole "Wavelet Thresholding Approach For Image Denoising", International Journal of Network Security \& Its Applications (IJNSA), Vol.3, No.4, July 2011

[3]. Chanchal Srivastava, Saurabh Kumar Mishra, Pallavi Asthana, G. R. Mishra, O.P. Singh “ Performance Comparison of Various Filters and Wavelet Transform for Image De-Noising," IOSR Journal of Computer Engineering (IOSR-JCE) Volume 10, Issue 1 (Mar. - Apr. 2013), PP 5563 ,

[4]. Usama S. Mohammed, H. A. Hamada "Image transmission over OFDM channel with rate allocation scheme and minimum peak-to-average power ratio" JOURNAL OF TELECOMMUNICATIONS, VOLUME 2, ISSUE 2, MAY 2010

[5]. Ezequiel Pérez Rodenas "QAM and PSK Modulation Schemes under Impulsive Noise”, April 2012 